\title{
Compact Multiband Interdigital-Coupled-Fed Planar Antenna with Stepped-Impedance Structures for Mobile Handsets
}

\author{
Tao Zhou, Yazi Cao, and Zhiqun Cheng \\ Hangzhou Dianzi University, Hangzhou, Zhejiang, China \\ Correspondence should be addressed to Yazi Cao; yazi.cao@hotmail.com
}

Received 9 February 2017; Revised 3 April 2017; Accepted 19 April 2017; Published 20 June 2017

Academic Editor: Miguel Ferrando Bataller

Copyright (c) 2017 Tao Zhou et al. This is an open access article distributed under the Creative Commons Attribution License, which permits unrestricted use, distribution, and reproduction in any medium, provided the original work is properly cited.

\begin{abstract}
A new compact multiband planar antenna combining an interdigital-coupled feeding line and one stepped-impedance structure is presented here. This antenna is capable of generating five resonant modes to cover the ISM $915 / 2400 / 5800 \mathrm{MHz}$ bands, GPS band, and IMT C-band, respectively. The five resonant frequencies covered by the proposed antenna can be adjusted individually by controlling the impedances and electrical lengths of the corresponding stepped-impedance sections. An additional advantage of the proposed stepped-impedance structure is its ability to suppress higher order resonance modes, thus filtering out unwanted interference. The proposed antenna utilizes a simple planar compact structure and occupies a small area of only $12 \times 30 \mathrm{~mm}^{2}$. Details of the antenna design and experimental results are presented and discussed.
\end{abstract}

\section{Introduction}

Mobile wireless communication handsets typically use multiband antennas to transmit and receive wireless signals to cover all required wireless communication frequency bands [1-4]. Because of its compact size and multiband performance, the planar inverted F-antenna (PIFA) is preferred for multiband antenna for wireless communication devices [57]. However, the ability to cover multiple bands while minimizing the structure of slot antennas is still a challenge for antenna designers. Furthermore, the PIFA typically exhibits performance limitations related to the radiating branches, not only generating the lower resonant modes but also exciting several higher order modes. These unexpected higher modes will complicate frequency tuning of the multiband antenna. Additionally, these unexpected higher order modes will affect the power amplifier or low-noise amplifier's performances and in turn degrade multiband antenna's radiation properties.

Here we present a novel compact multiband planar antenna formed by the interdigital-coupled feeding line, one stepped-impedance line, and one shorted stripe line connected to the ground plane of the mobile handsets. The antenna feeding line comprises an interdigital structure for enhancing signal coupling and to allow more flexibility for wideband impedance matching [8]. The stepped-impedance line forms folded stripe lines with different impedances and electrical lengths. This stepped-impedance structure is introduced to control five resonant modes to cover ISM 915/2400/5800 bands, GPS band, and IMT C-band operations, respectively. An additional advantage of using stepped-impedance structure includes the ability to suppress higher order resonant frequencies thus filtering out unwanted interference. Design consideration and experimental performances of the proposed antenna are studied and presented.

\section{Antenna Design}

Figure 1 shows the structure of the proposed interdigitalcoupled-fed planar antenna. The proposed antenna mainly comprises the FR4 substrate, a ground plane under the substrate, and a radiating metal portion on the top of the substrate. Under the upside of the substrate, there is one ground-clear area under the radiating metal portion. The radiating metal portion comprises the interdigital-coupled feeding line, the stepped-impedance line, and one shorted line. The interdigital-coupled feeding line connecting a signal source forms a three-finger interdigital structure. One end of the interdigital-coupled-fed line is of the L-shape. The stepped-impedance line includes six bending stepped lines 


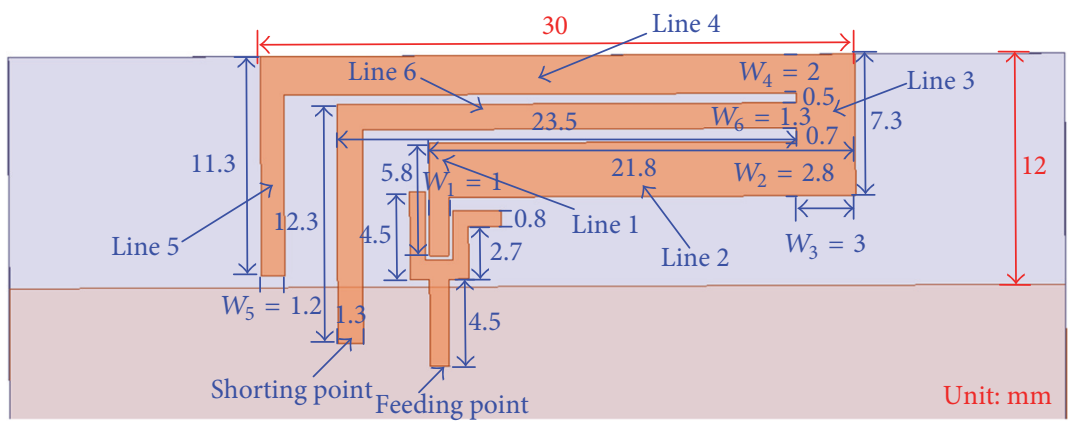

(a)

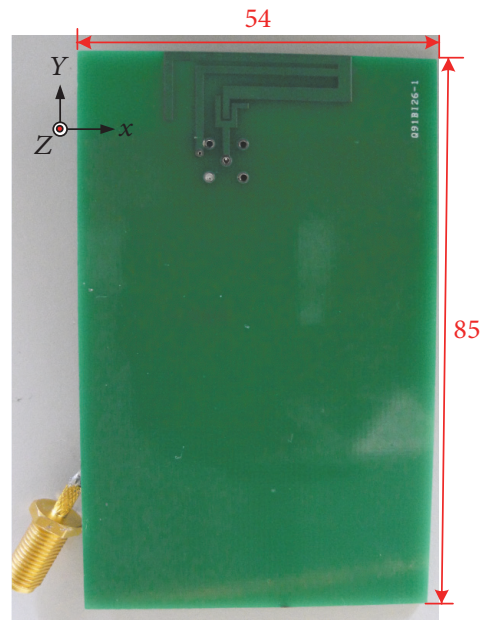

(b)

FIgURE 1: Configuration of the proposed antenna on a $1.6 \mathrm{~mm}$ FR4 substrate. (a) Detailed dimensions of radiating element (front view). (b) Photo of the antenna prototype.

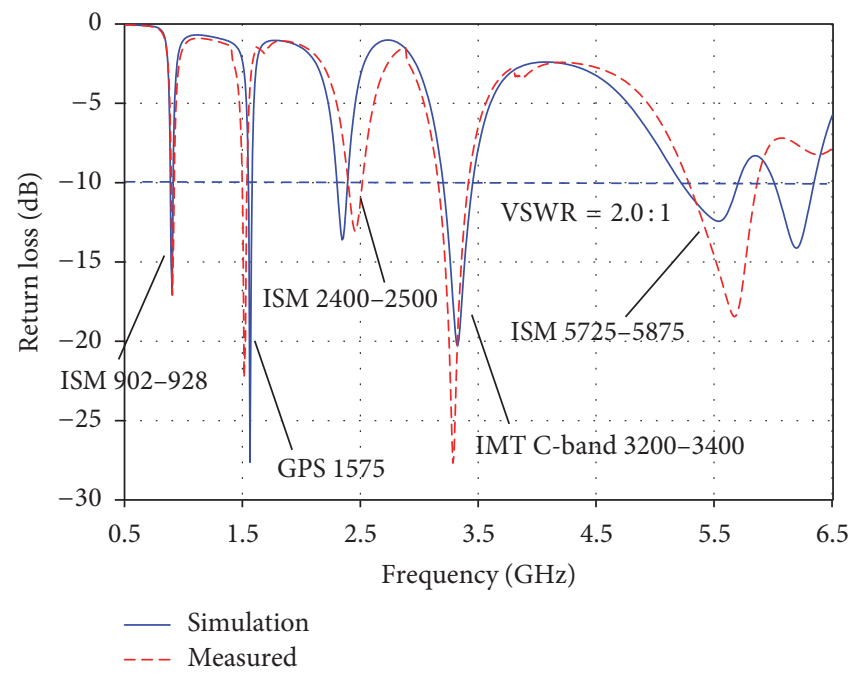

FIGURE 2: Measured and simulated return loss for the proposed antenna.

with different impedances and electrical lengths. The shorted line is connected to ground plane through one via hole.

Based on generalized transmission line theory, the multimode property of this stepped-impedance line can be characterized and determined by the impedances and electrical lengths of adjacent folded stripe lines [9-11]. In this proposed structure, the folded stripe lines control the excitations of the antenna bands centered at $915 \mathrm{MHz}, 1575 \mathrm{MHz}, 2400 \mathrm{MHz}$, $3200 \mathrm{MHz}$, and $5800 \mathrm{MHz}$ to cover ISM $915 / 2400 / 5800$ bands, GPS band, and IMT C-band operations, respectively. These five resonant modes generated by the corresponding respective stepped sections can be controlled individually. A ground plane with a length of $73 \mathrm{~mm}$ and a width of $54 \mathrm{~mm}$ is printed on the $1.6 \mathrm{~mm}$ thick FR4 substrate of relative permittivity of 4.4 and loss tangent of 0.02 . The total size of FR4 corresponded to the width and length of $85 \mathrm{~mm}$ and $54 \mathrm{~mm}$, respectively. The signal source feeds the interdigitalcoupled lines and is subsequently coupled into the steppedimpedance lines. Both measurement and simulated results including the peak gain, radiation efficiency, and radiation pattern are presented next to validate our proposed structure.

\section{Experimental Results and Discussion}

Figure 2 shows the measured and simulated return loss of the proposed antenna with the dimensions given in Figure 1. The measured data agrees very well with the simulated results obtained from the Ansoft simulation software HFSS [12]. The low band exhibits a measured 2.0:1 VSWR ( $-10 \mathrm{~dB}$ return loss) bandwidth covering ISM 915/2400/5800 bands (902 928 MHz, 2400-2500 MHz, and 5725-5875 MHz), GPS $1575 \mathrm{MHz}$ band, and IMT C-band $3200-3400 \mathrm{MHz}$ operation.

The measured gain radiation patterns of the constructed prototype are shown for the 915, 1575, 2450, 3200, and $5875 \mathrm{MHz}$ frequency bands in Figure 3. At $915 \mathrm{MHz}$, the omnidirectional dipole-like radiation patterns can be seen, 


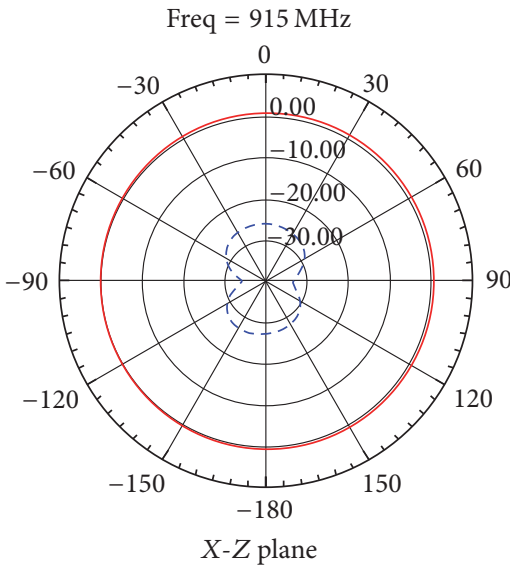

$---G_{\theta}$

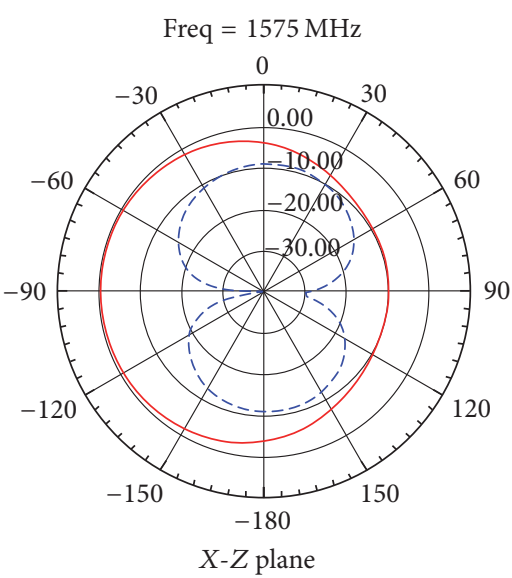

$---G_{\theta}$

$-G_{\varphi}$

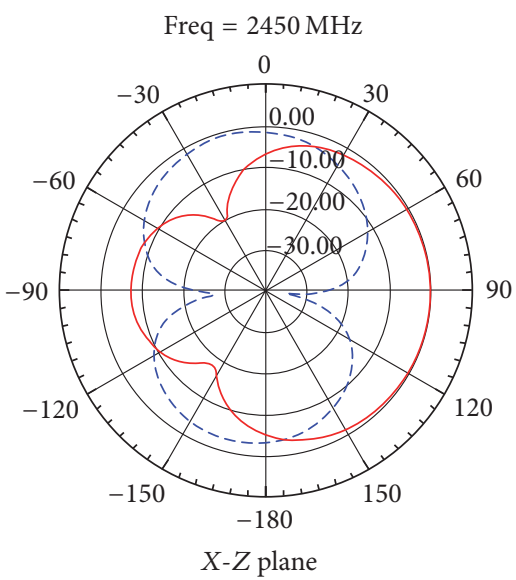

$---G_{\theta}$

$-G_{\varphi}$

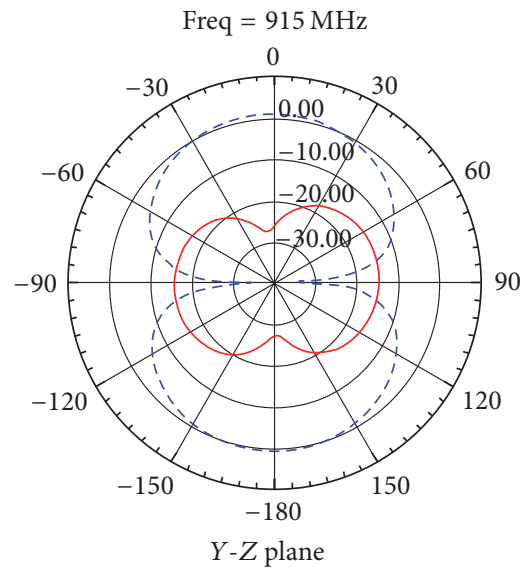

$$
---G_{\theta}
$$

(a)

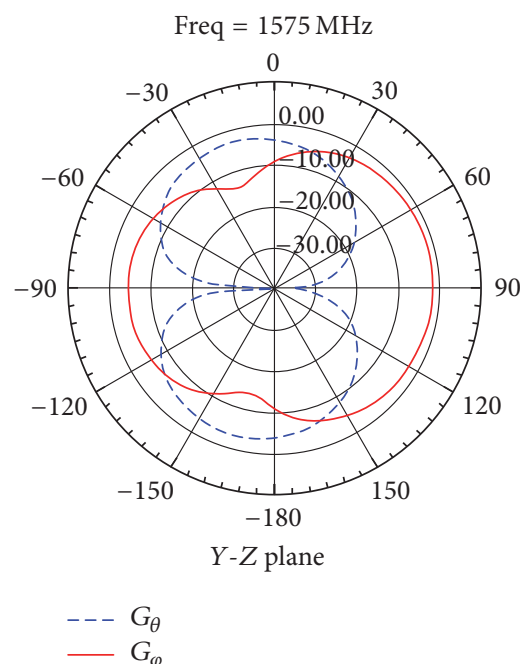

(b)

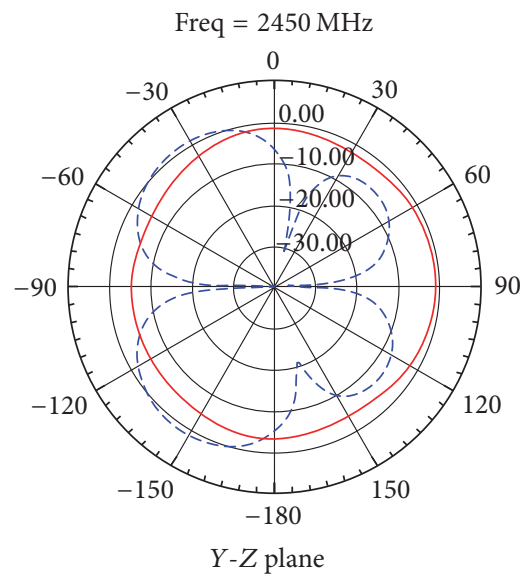

$---G_{\theta}$
$-G_{\varphi}$

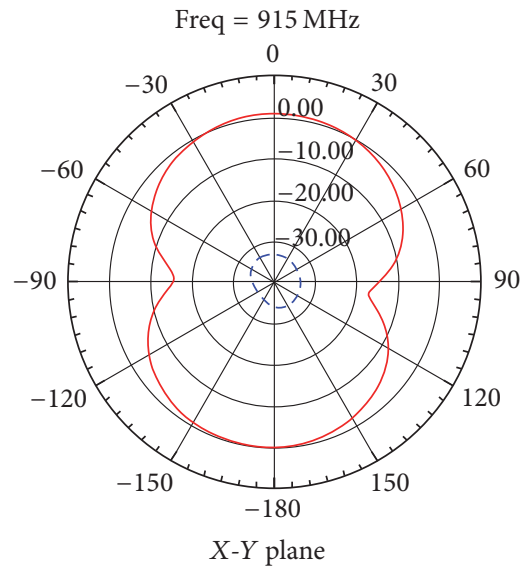

$$
---G_{\theta}
$$
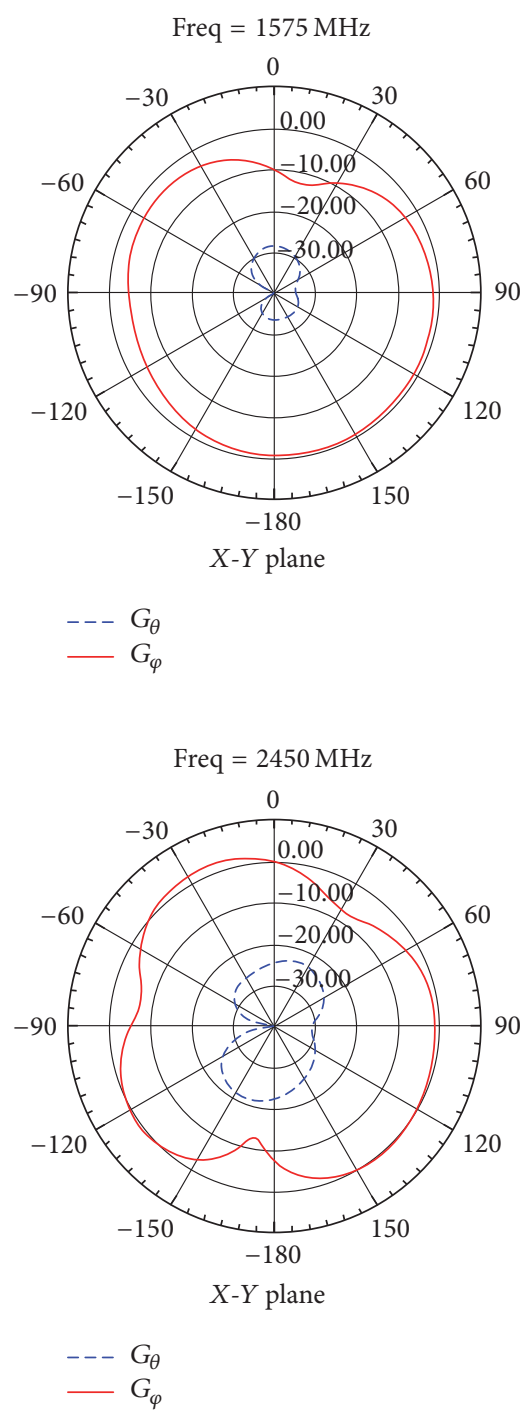

(c)

Figure 3: Continued. 


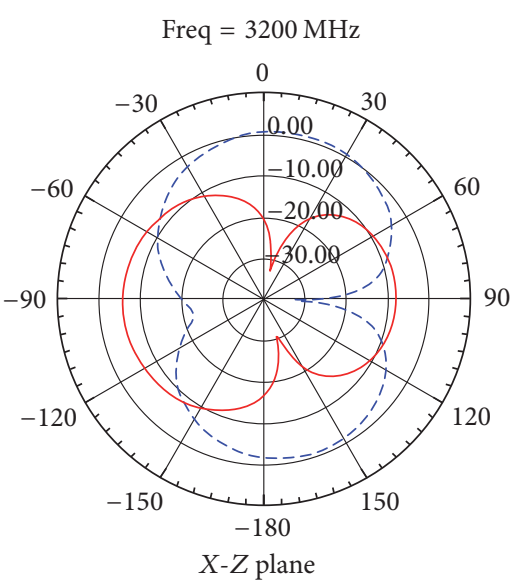

$---G_{\theta}$
$-G_{\varphi}$

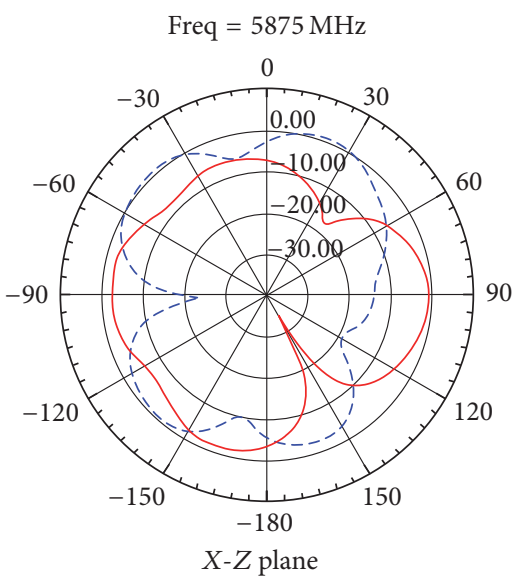

$---G_{\theta}$
$-G_{\varphi}$

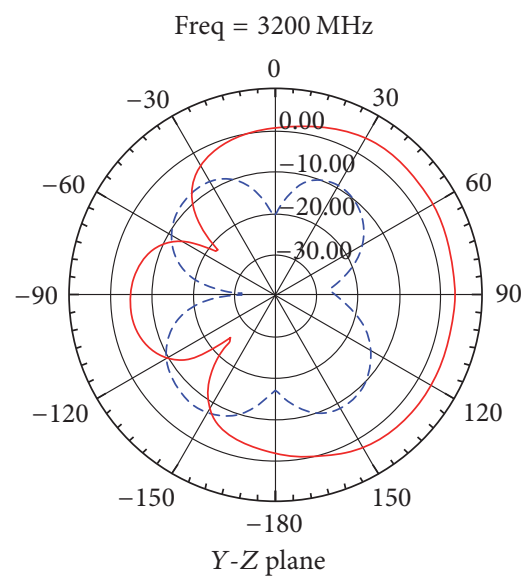

$---G_{\theta}$

$-G_{\varphi}$

(d)

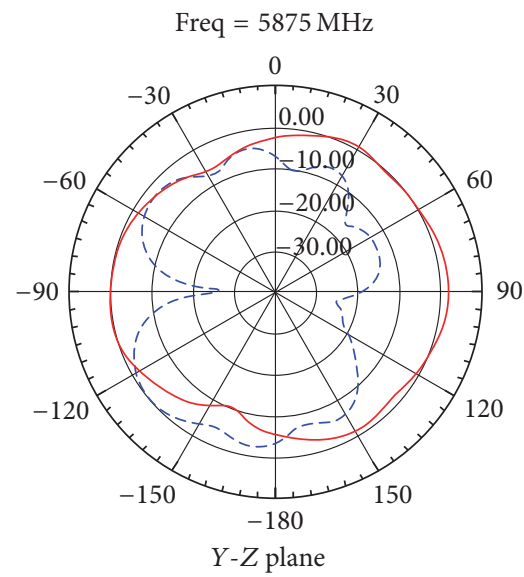

$---G_{\theta}$

$-G_{\varphi}$

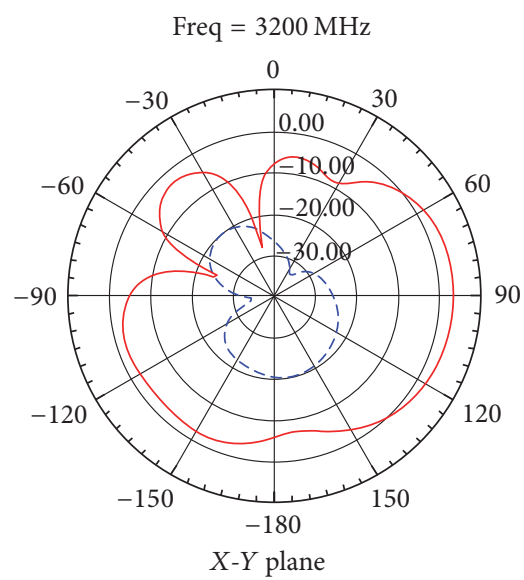

$---G_{\theta}$

$-G_{\varphi}$

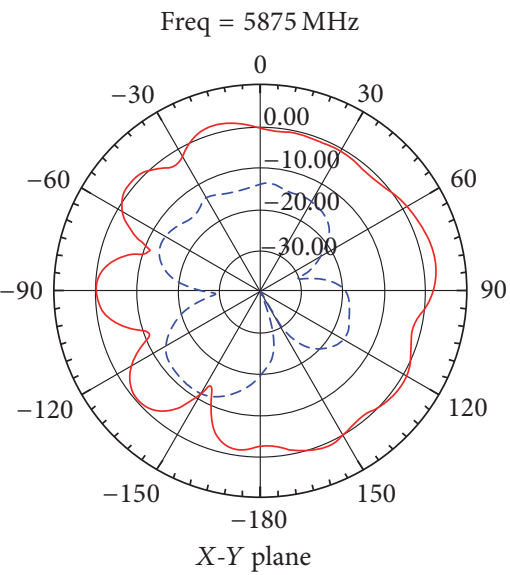

$---G_{\theta}$

(e)

Figure 3: Measured gain radiation patterns at (a) $915 \mathrm{MHz}$; (b) $1575 \mathrm{MHz}$; (c) $2450 \mathrm{MHz}$; (d) $3200 \mathrm{MHz}$; and (e) $5875 \mathrm{MHz}$.

and the radiation patterns for higher frequencies show similar agreement with expected/simulated results. For the 1575, 2450, 3200, and $5875 \mathrm{MHz}$ frequency bands, the measured gain radiation patterns are comparable to those observed in conventional internal mobile phone antennas.

For the lower band at ISM $915 \mathrm{MHz}$, the measured gain varied from about 0.4 to $0.7 \mathrm{dBi}$, and the antenna radiation efficiency is better than $50 \%$ over $902 \sim 928 \mathrm{MHz}$. For the upper bands including GPS $1575 \mathrm{MHz}$, ISM 2450/5800 MHz, and IMT C-band $3200 \mathrm{MHz}$, the antenna gain varies from 1.0 to $3.0 \mathrm{dBi}$, with the radiation efficiency better than $60 \%$. The measured peak gain and radiation efficiency results of the proposed antenna are acceptable for practical application.

In order to show the resonant modes of the proposed antenna, the simulated surface current distributions on the radiating metal portion and the ground plane at 915, 1575, 2450, 3200, and $5875 \mathrm{MHz}$ are shown in Figure 4. As shown in Figure 4(a), the strong excited surface currents at $915 \mathrm{MHz}$ are flowing along the folded stripe line 6 as defined in Figure 1. As shown in Figure 4(b), the strong excited surface currents at $1575 \mathrm{MHz}$ are flowing along the folded stripe line 4 . As shown in Figure 4(c), the strong excited surface currents at $2450 \mathrm{MHz}$ are flowing along the folded stripe lines 2, 3, and 6. As shown in Figure 4(d), the strong excited surface currents at $3300 \mathrm{MHz}$ are flowing along the folded stripe lines 2, 4, and 5. As shown in Figure 4(e), the strong excited surface currents at $5875 \mathrm{MHz}$ are flowing along the folded stripe lines 1 and 2. These current distribution characteristics indicate that these five resonant modes can be tuned and controlled by the corresponding impedances and electrical lengths of folded stripe lines 1-6.

Furthermore, Figure 5 depicts the simulated return loss variations with the different widths $W_{2}, W_{3}, W_{4}, W_{5}$, and $W_{6}$ of folded stripe lines $2,3,4,5$, and 6 , respectively. The obtained 


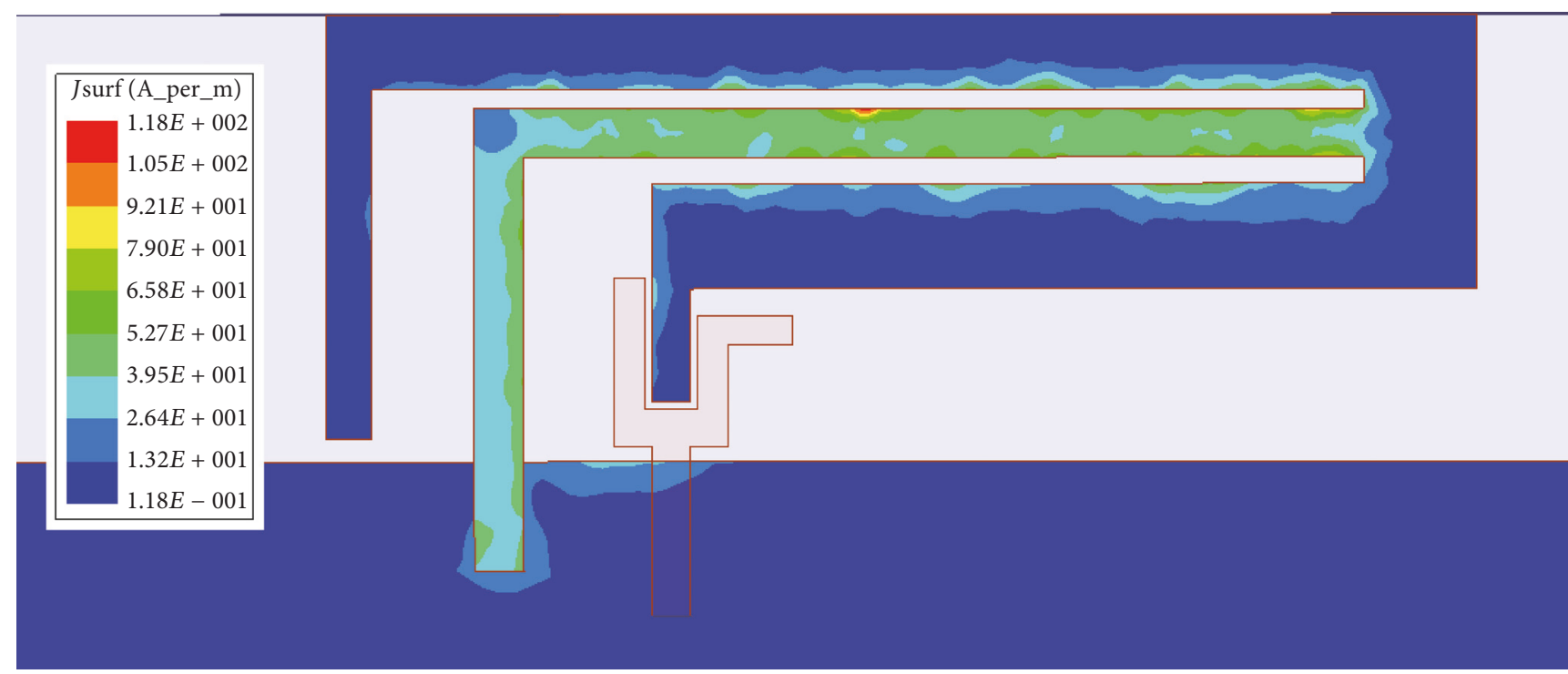

(a)

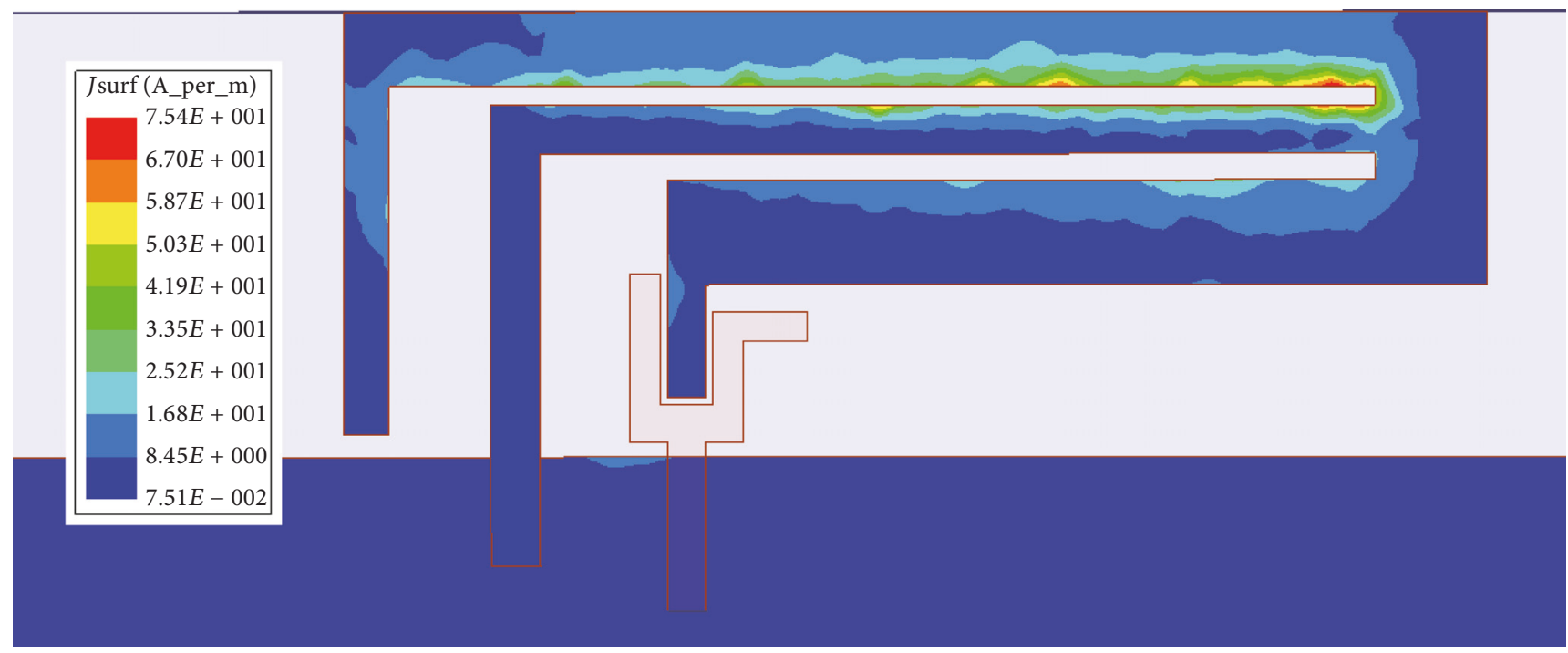

(b)

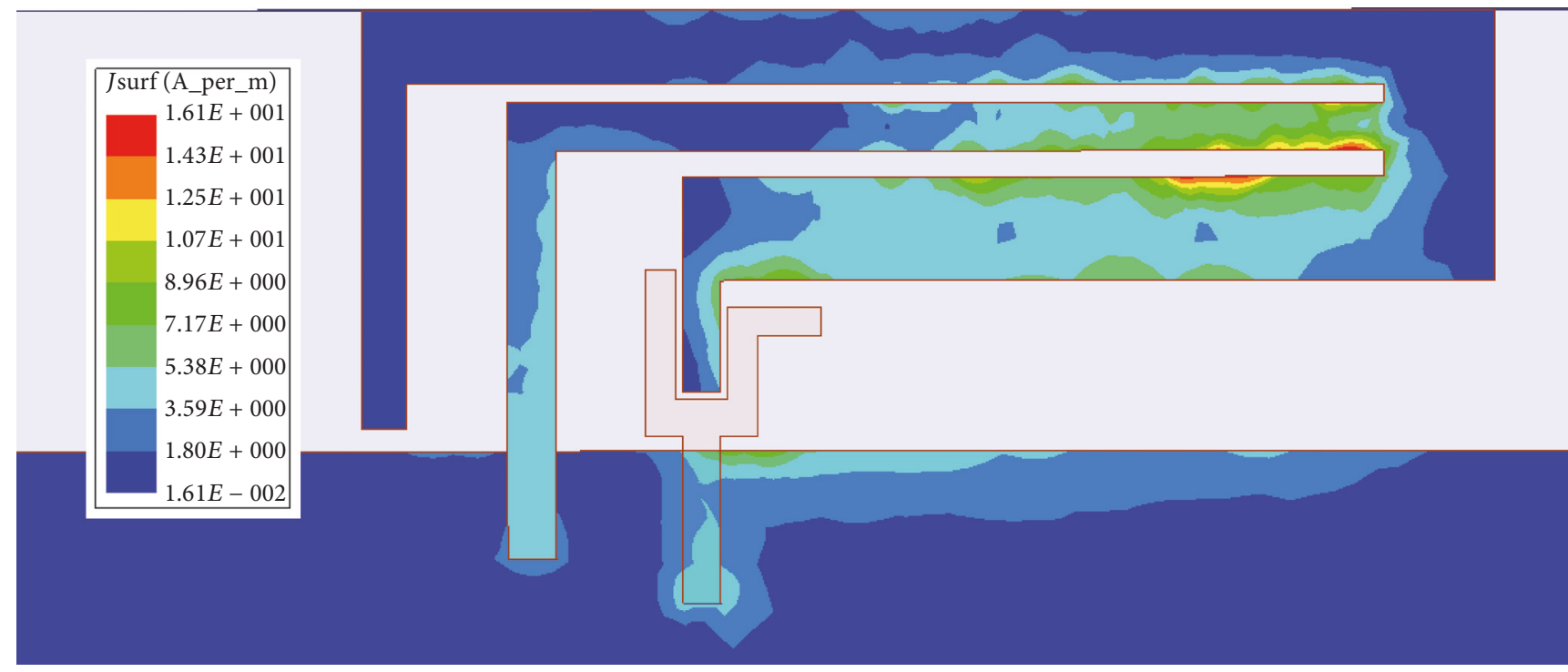

(c)

FIgURE 4: Continued. 


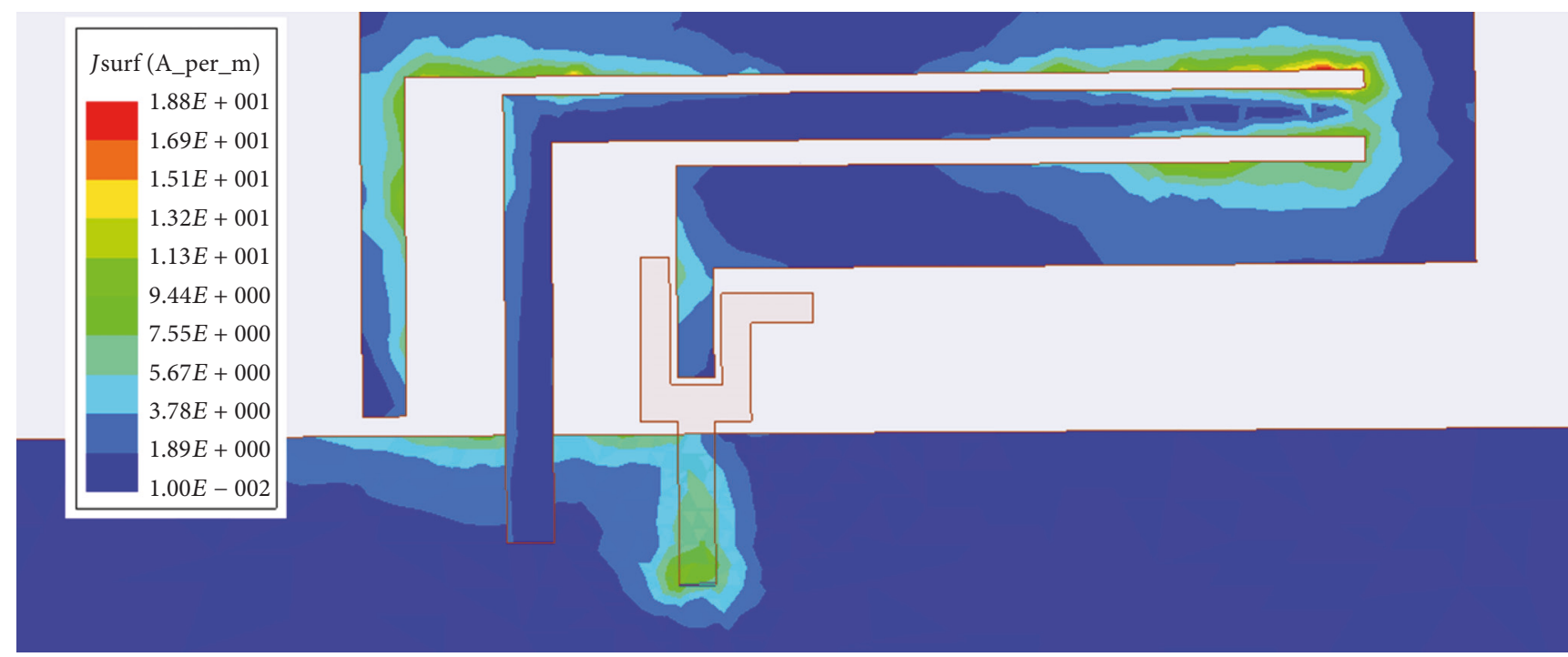

(d)

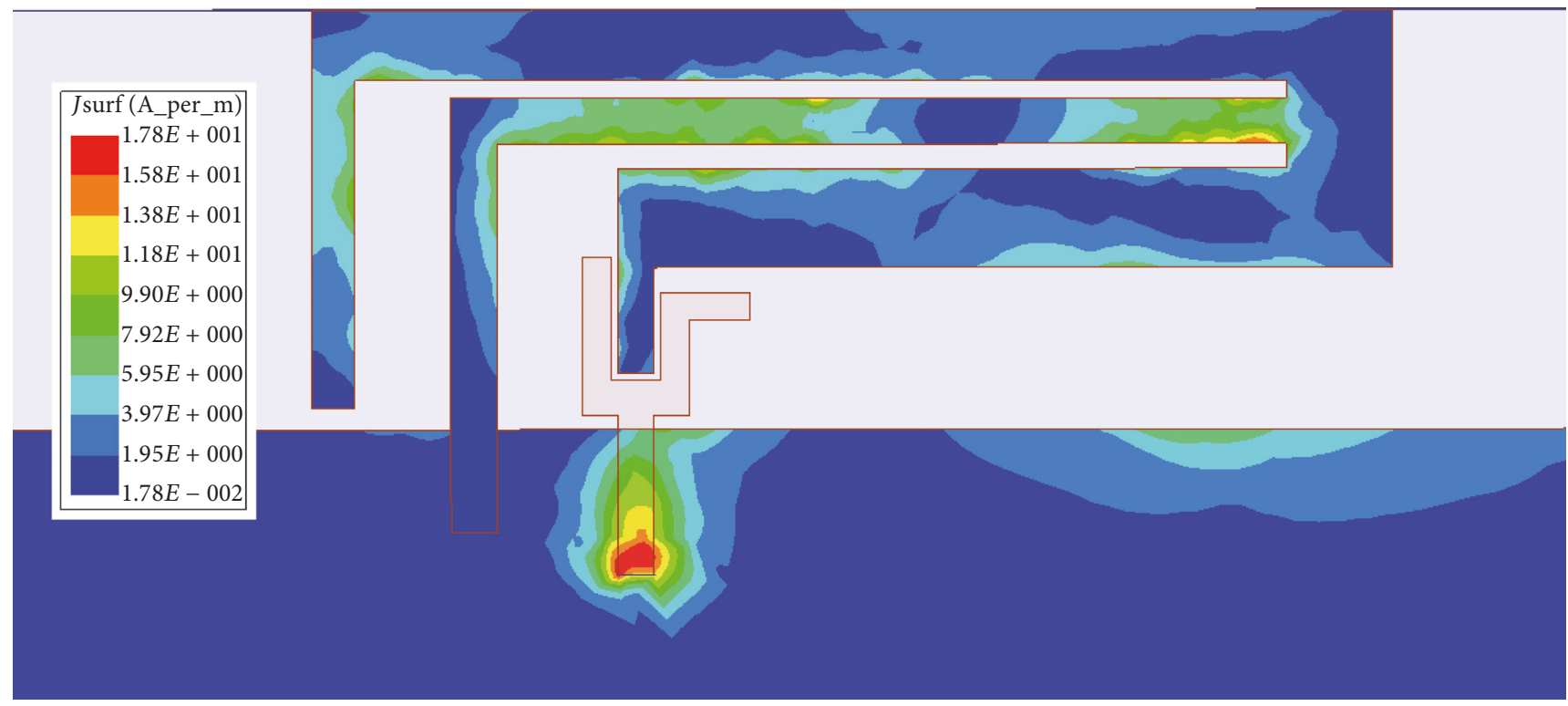

(e)

FiguRE 4: Simulated current distributions on the radiating metal portion and the ground plane at (a) $915 \mathrm{MHz}$; (b) $1575 \mathrm{MHz}$; (c) $2450 \mathrm{MHz}$; (d) $3300 \mathrm{MHz}$; and (e) $5875 \mathrm{MHz}$.

result indicates that these five resonant frequencies can be adjusted effectively by the corresponding folded stripe lines. It agrees with the current distributions as shown in Figure 4.

\section{Conclusion}

In this letter we report the design and fabrication of a novel multiband printed antenna formed by interdigital-coupled feeding line, one stepped-impedance line, and one shorted stripe line connected to the ground plane of the mobile handsets. A prototype of the proposed antenna has been successfully realized and experimental validation matches expected results. The proposed antenna utilizes a simple planar structure with a small area of only $12 \times 30 \mathrm{~mm}^{2}$. This antenna is able to generate five resonant modes to cover the ISM 915/2400/5800 frequency bands, GPS band, and IMT C-band operation. These five resonant modes can be controlled individually by the corresponding steppedimpedance lines. This merit would be attractive for antenna designers since it enables optimization and tuning of the antenna by adjusting the geometrical parameters of each individual corresponding stepped-impedance lines without disturbing adjacent sections. 

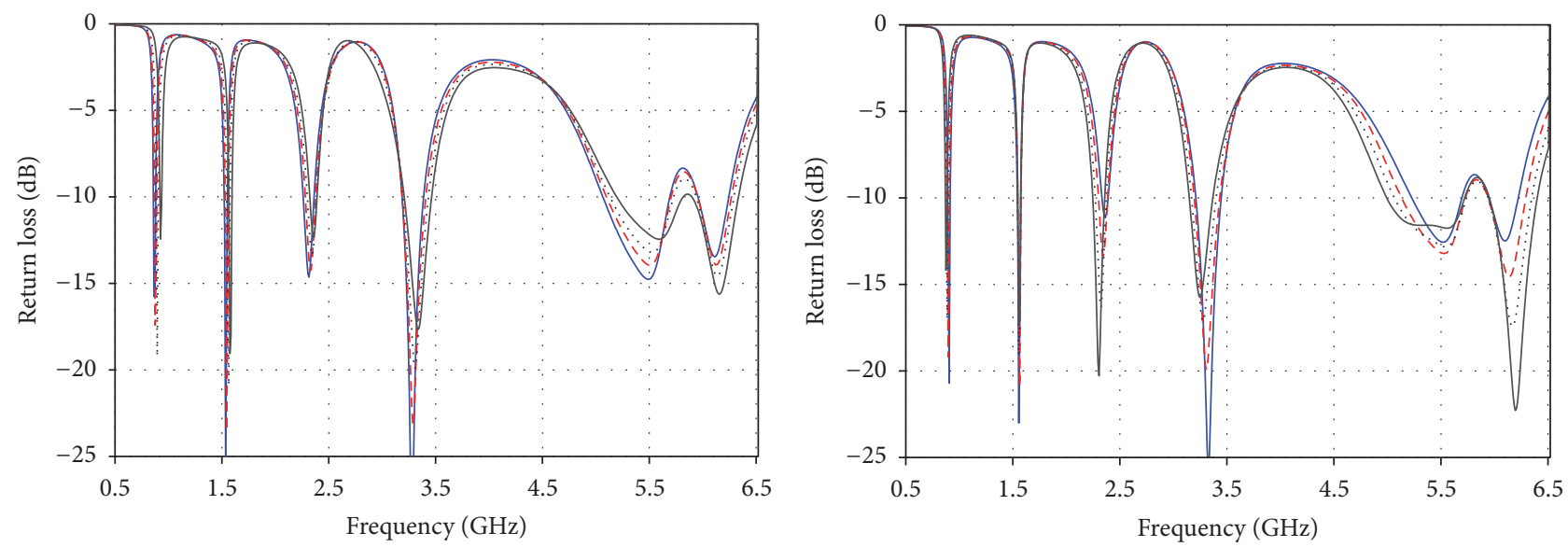

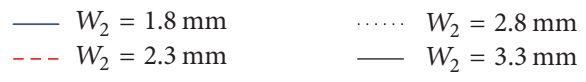

(a)

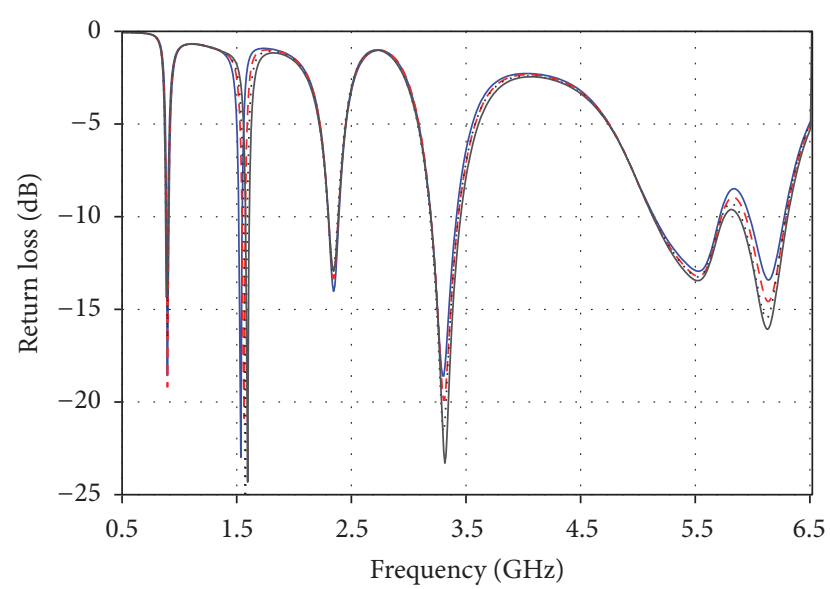

$$
\begin{aligned}
\ldots \ldots . W_{4} & =2.5 \mathrm{~mm} \\
-W_{4} & =3 \mathrm{~mm}
\end{aligned}
$$

(c)

$$
\begin{array}{ll}
-W_{3}=2 \mathrm{~mm} & \ldots \ldots W_{3}=4 \mathrm{~mm} \\
--W_{3}=3 \mathrm{~mm} & -W_{3}=4 \mathrm{~mm}
\end{array}
$$

(b)

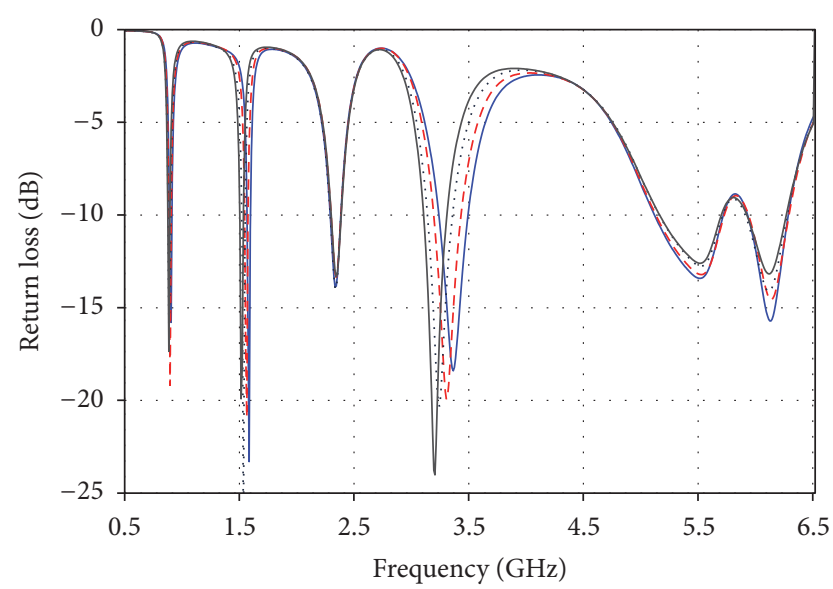

$-W_{5}=0.8 \mathrm{~mm}$

- - $W_{5}=1.2 \mathrm{~mm}$

$$
\begin{aligned}
\ldots . . . & W_{5}=1.6 \mathrm{~mm} \\
W_{5} & =2 \mathrm{~mm}
\end{aligned}
$$

(d)

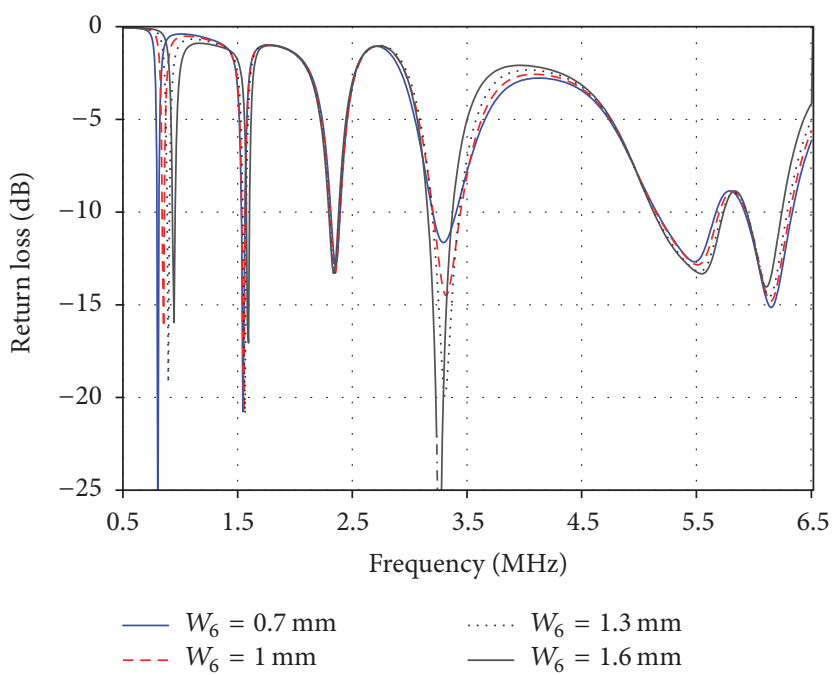

(e)

FIGURE 5: Simulated return loss of the proposed antenna with variations of widths $W_{2}(\mathrm{a}), W_{3}(\mathrm{~b}), W_{4}(\mathrm{c}), W_{5}(\mathrm{~d})$, and $W_{6}(\mathrm{e})$. 


\section{Conflicts of Interest}

The authors declare that they have no conflicts of interest.

\section{Acknowledgments}

This work was supported by the National Nature Science Foundation of China under Grants 61411136003 and 61331007, the Zhejiang Provincial Natural Science Foundation of China under Grant LZ14F040001, and the Zhejiang Provincial Science and Technology Program under Grant 2017C31066.

\section{References}

[1] B. Yuan, Y. Cao, G. Wang, and B. Cui, "Slot antenna for metal-rimmed mobile handsets," IEEE Antennas and Wireless Propagation Letters, vol. 11, pp. 1334-1337, 2012.

[2] L. Hu and W. Hua, "Wide dual-band CPW-fed slot antenna," Electronics Letters, vol. 47, no. 14, pp. 789-790, 2011.

[3] B. Yuan, Y. Cao, and G. Wang, "A miniaturized printed slot antenna for six-band operation of mobile handsets," IEEE Antennas and Wireless Propagation Letters, vol. 10, pp. 854-857, 2011.

[4] S.-W. Chen, D.-Y. Wang, and W.-H. Tu, "Dual-band/triband/broadband CPW-Fed stepped-impedance slot dipole antennas," IEEE Transactions on Antennas and Propagation, vol. 62, no. 1, pp. 485-490, 2014.

[5] Y. Cao, B. Yuan, and G. Wang, "A compact multiband openended slot antenna for mobile handsets," IEEE Antennas and Wireless Propagation Letters, vol. 10, pp. 911-914, 2011.

[6] Y.-L. Ban, Y.-F. Qiang, Z. Chen, K. Kang, and J.-H. Guo, "A dual-loop antenna design for hepta-band WWAN/LTE metalrimmed smartphone applications," Institute of Electrical and Electronics Engineers. Transactions on Antennas and Propagation, vol. 63, no. 1, pp. 48-58, 2015.

[7] D. Wu, S. W. Cheung, and T. I. Yuk, "A compact and lowprofile loop antenna with multiband operation for ultra-thin smartphones," Institute of Electrical and Electronics Engineers. Transactions on Antennas and Propagation, vol. 63, no. 6, pp. 2745-2750, 2015.

[8] J.-X. Liu and W.-Y. Yin, "A compact interdigital capacitorinserted multiband antenna for wireless communication applications," IEEE Antennas and Wireless Propagation Letters, vol. 9, pp. 922-925, 2010.

[9] B. Yu, B. Jia, and Z. Zhu, "Compact tri-band bandpass filter with stub-loaded stepped-impedance resonator," Electronics Letters, vol. 51, no. 9, pp. 701-703, 2015.

[10] C.-J. Wang and L.-T. Chen, "Modeling of stepped-impedance slot antenna," IEEE Transactions on Antennas and Propagation, vol. 62, no. 2, pp. 955-959, 2014.

[11] Y. Sung, "UWB monopole antenna with two notched bands based on the folded stepped impedance resonator," IEEE Antennas and Wireless Propagation Letters, vol. 11, pp. 500-502, 2012.

[12] HFSS Version 17, ANSYS, Canonsburg, Pa, USA, 2016. 


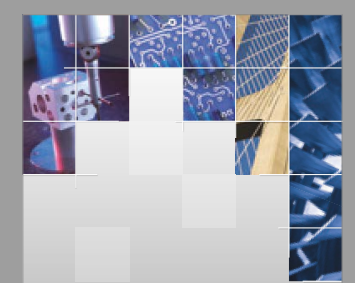

\section{Enfincering}
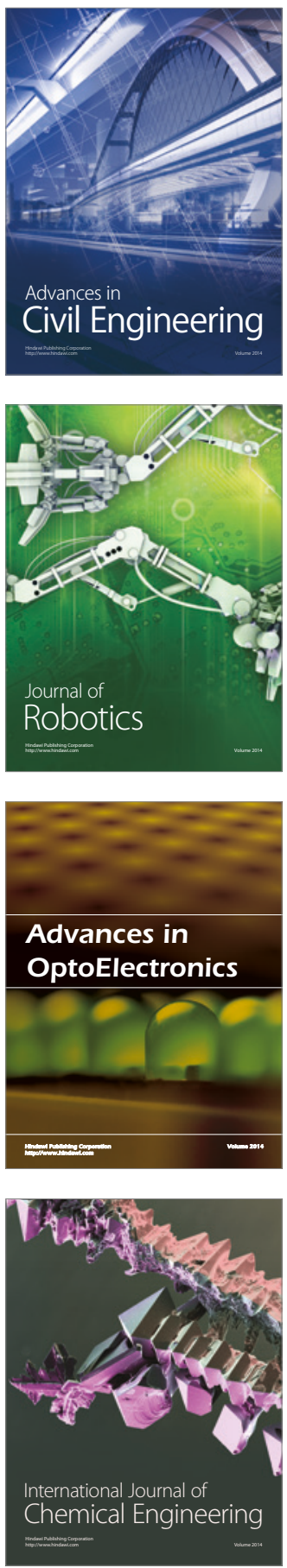

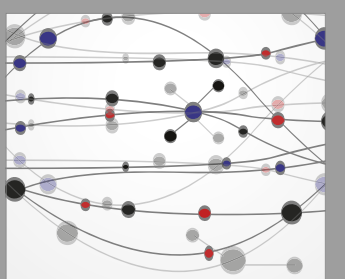

The Scientific World Journal

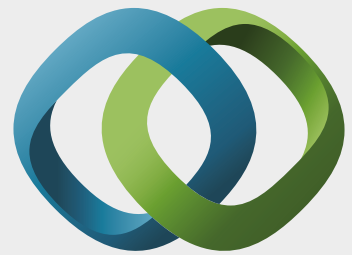

\section{Hindawi}

Submit your manuscripts at

https://www.hindawi.com
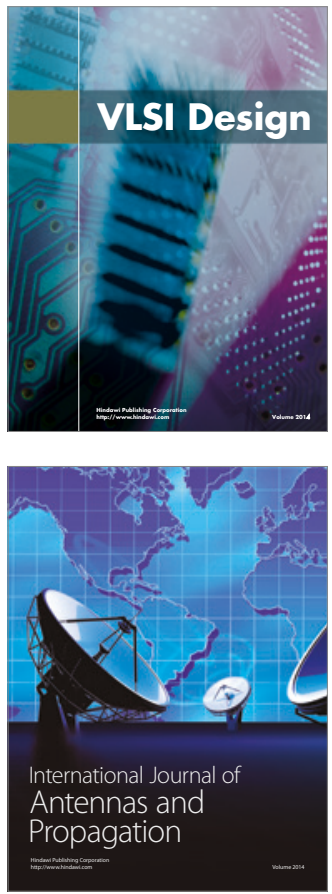

\section{Rotating}

Machinery
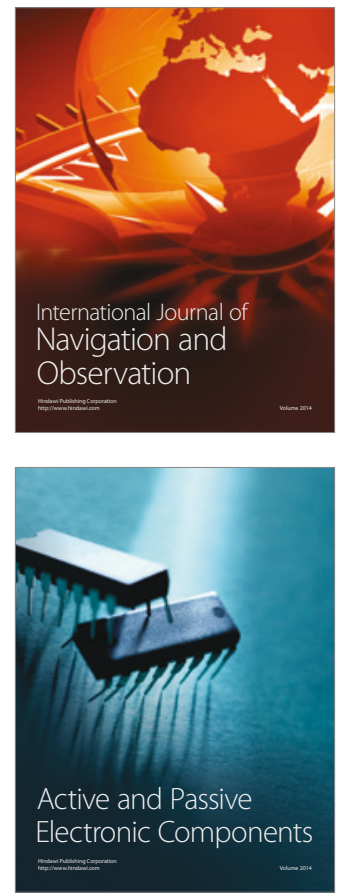
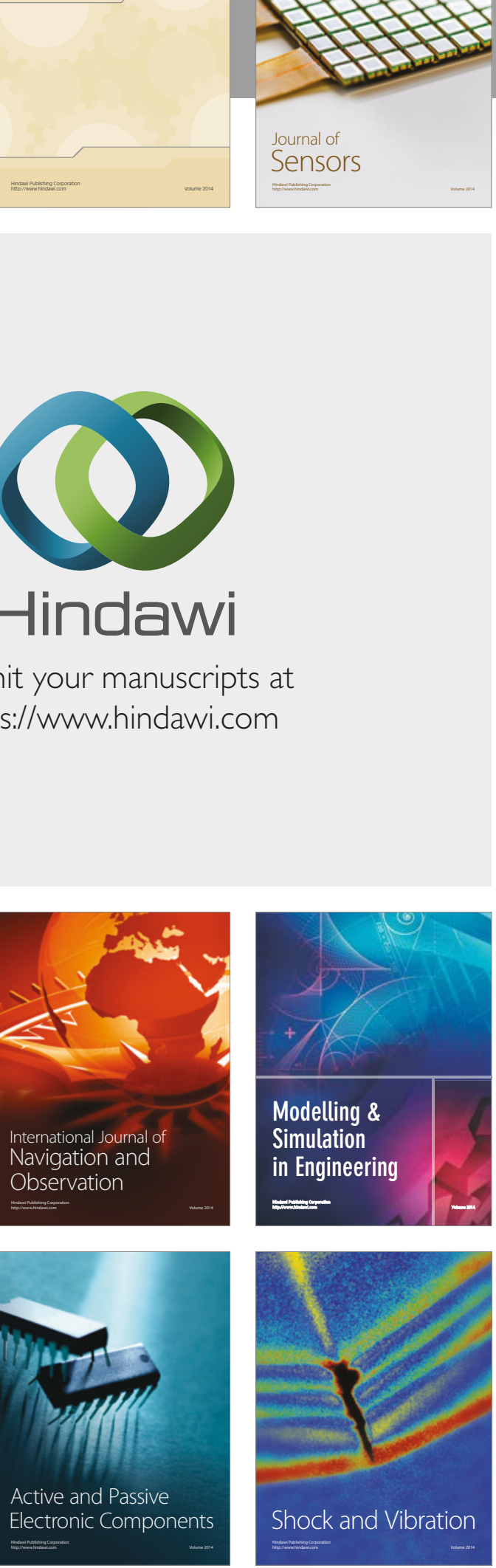
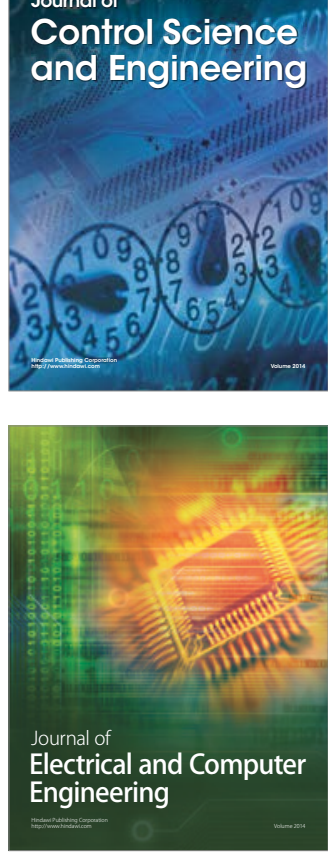

Distributed

Journal of

Control Science

and Engineering
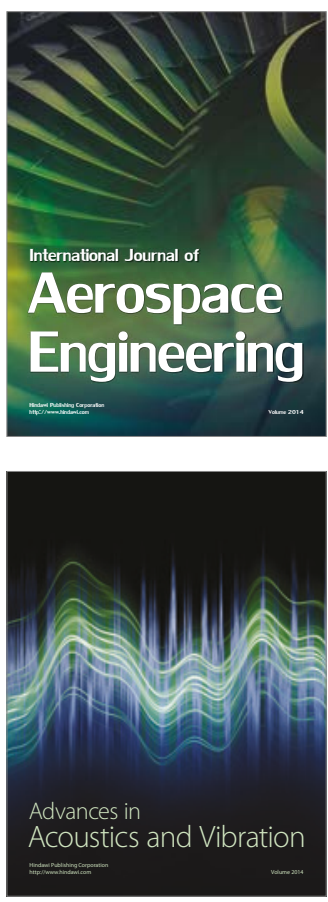

Sensor Networks 